\title{
https://doi.org/10.48009/2_iis_2006_333-338 \\ INFORMATION SYSTEMS ETHICS IN DEVELOPED \& DEVELOPING ECONOMIES: COMPARING BOLIVIA, OMAN, SOUTH KOREA, \& THE UNITED STATES
}

\author{
Thomas S.E. Hilton, University of Wisconsin - Eau Claire, Hiltonts@UWEC.edu \\ Adriana Martinez Santa Cruz, University of Wisconsin - Eau Claire, martinea@uwec.edu \\ Se-Hyung "David" Oh, Thunderbird University, docoh@ hotmail.com \\ Husain M. Al-Lawati, Omani College of Banking \& Financial Studies, husain@cbfs.edu.om
}

\begin{abstract}
A convenience sample of 690 business employees completed a 30-item, three-section IS ethics questionnaire, 129 in the western USA, 176 in Oman, 215 in South Korea, and 170 in Bolivia. Section 1 concerned employee use of employer IS resources for personal entertainment; section 2 concerned employee use of employer IS resources for the gain of self, family, or friends; and section 3 concerned employer monitoring of employee use of employer IS resources. Statistically significant differences occurred on 29 items across all sections; 23 represented differing degrees of commitment but overall agreement on the ethicality of a behavior; 6 represented disagreement regarding the ethicality of a behavior. Of the 6 disagreements, 2 were in section 1 and concerned after-hours use of IS resources, and 4 were in section 3 and concerned giving prior notice when monitoring employees. All samples tended to favor the employer over the employee, though less in section 3 than in sections 1 and 2. Section 3 generated the greatest differences among the samples. Bolivia and Oman showed the most agreement with the other cultures. The US and South Korean samples showed the least agreement, clustering with each other in pairwise comparisons on only two items, both in section 2. The US sample was most employer-centric on 23 items, and the South Korean sample was most employee-centric on 20 items.
\end{abstract}

Keywords: Information Systems, Ethics, International, Bolivia, Oman, South Korea, United States of America

\section{INTRODUCTION}

Information is very personal, being produced and consumed by the human mind as it is [8, 10]. Because of this, every culture has developed powerful norms for identifying right or wrong uses of information [13]. We call these norms information ethics. Information sharing across cultures has been the forerunner to and continues as the foundation of unprecedented and increasing synergy in international commerce [12]. It thus becomes crucial to clarify culture-specific information ethics as they influence these IT-enabled interactions among cultures [16].

For this study, we selected four different nations with which to compare information ethics across cultures: the Republic of Bolivia, the Sultanate of Oman, the Republic of South Korea, and the United States of America. These four nations represent a large part of the spectrum of the World Bank's Gross National Income (GNI) rating system. The Republic of Bolivia has a lower-middle GNI rating, the Sultanate of Oman has an upper-middle rating, the Republic of South Korea a high rating, and the United States of America a high rating.

The purpose of this study is to help clarify similarities and differences among the four cultures so as to facilitate effective cross-cultural communication and commerce. Although we do not assert that the IS ethics in each of these countries is entirely typical of IS ethics of all countries with the same GNI rating, we believe that each provides a basis for fruitful comparison.

\section{ETHICS ACROSS DEVELOPED AND DEVELOPING ECONOMIES}

Ethical behavior is influenced by various factors such as "societal environment, belief system, personal values, personal environment, professional environment, legal environment, business environment, moral obligation and consequences" [7]. Therefore, we first studied the basis of ethics in each of the four cultures. We provide a brief summary here:

\section{US Business Ethics}

Although historically based on heterodox Christian morality, ethics decisions of US businesspeople seem to be a function of three philosophies of secularhumanism: 
- recognition of self-evident rights and duties (per Immanuel Kant-see [5]),

- the interplay of justice for society and fairness to individuals (per John Rawls—see [11]), and

- consideration of practical consequences (per William James as expanded by John Stuart Mill—see [9]).

\section{Omani Business Ethics}

Ethics decisions of Omani businesspeople are based on Islam. "Akhlaq," the term for ethics used by Muslims, is also the term for morality; hence, ethics as distinct from morality has no definite equivalent in the Omani culture. Abeng [1] states, "Besides its general appreciation for the vocation of business, the Qur'an often speaks about honesty and justice in trade."

\section{South Korean Business Ethics}

As a country that has long followed the Confucian tradition, Korean culture favors the benefit of an organization or society over that of an individual [17]. De Mente [4] comments, "The Korean criteria for sin are not based as much on universal absolutes as on the effect actions have on individuals, on the family, on co-workers and friends, and on society at large. Korean business ethics, then, revolves around building and maintaining relationships within the context of organizational harmony and accord.

\section{Bolivian Business Ethics}

In Bolivia, Catholic Christianity and what is euphemistically referred to as "the business environment" are the two most important factors that influence business ethics. The Ten Commandments are typical of the Catholic perspective. The business environment, on the other hand, is ruled by corruption, "the misuse of entrusted power for private gain" [14]. Transparency International ranks Bolivia 122 of 146 countries in corruption, or among the 15\% most corrupt [15]. The ethical business person in Bolivia is described as one who has "integrity and social responsibility" [3], but such business people are an acknowledged rarity.

\section{Summary of Business Ethics}

Despite unequivocal differences, we were gratified to found a degree of similarity within US, Omani, Korean, and Bolivian business ethics. The religionbased morality that underlies business ethics in all four cultures indicates the existence of a foundation for IS ethics that transcends culture to facilitate effective information exchange worldwide. We note, however, that significant vagueness remains in all four definitions because terms such as honesty, justice, morality, and humaneness are left undefined. That is, similarities notwithstanding, these definitions leave significant doubt as to just what uses of information would be considered right or wrong in the US, Omani, Bolivian, or South Korean cultures. Hence, this study.

\section{THEORETICAL FRAMEWORK}

Space does not permit explication of the theoretical framework for this study and its derivation from the business ethics literature. Suffice it to say that the theoretical framework upon which this study was based can be expressed in these terms:

Ethics choices are influenced by culture, gender, age, education level, and job rank. Ethics choices are operationalized as employee uses of employer IS resources and employer monitoring of employee use of employer IS resources.

\section{METHOD}

This research is essentially descriptive and correlational since we endeavor to describe, compare and identify relationships between different variables that influence business information ethics attitudes of different populations such as culture, gender, age, education level, and job rank. Since we used a convenience sample, the level of generalizability is unknown. Data were gathered via a self-administered questionnaire. For the Omani, South Korean, and US samples, we used a paper survey; for the Bolivian sample we used an Internet survey.

The survey contains 30 one-sentence scenarios in three broad areas:

- 12 items on employee use of employer IS resources for personal entertainment,

- 12 items on employee use of employer IS resources for gain (either their own or that of friends or family), and

- 6 items on employer monitoring of employee use of employer IS resources.

Respondents rated the behavior in each scenario on a 5-point Likert-type scale from "usually unethical" to "usually ethical" [2].

We obtained an overall response rate of $39.45 \%$ $(\mathrm{n}=690)$. The Omani rate was $70.4 \%(\mathrm{n}=176)$, the South Korean $86 \%(n=215)$, the US $45.6 \%(n=129)$, and the Bolivian 17.5\% $(n=170)$. The low Bolivian response rate was because it was Internet-delivered 
(see [6]); however, because a very large email list was used for the Bolivian sample, actual respondent numbers were comparable across the four cultures.

The data from the four cultures were compared via analysis of variance (ANOVA, $\alpha=0.025$ rather than .05 to decrease the risk of Type I errors in interpreting statistically significant results), to identify significant variation in the three types of scenarios (personal entertainment, gain, and monitoring). Also, to check the effect of non-culture variables (sex, age, education level, and position) on responses, stepwise multiple regression analysis $(\alpha=$ $0.05)$ was done.

\section{FINDINGS}

The main purpose of this study is to identify specifics of how the western US, Bolivian, Omani, and South Korean cultures are similar or different in deciding what is right and wrong in information systems (IS) use. To explore the similarities and differences in IS ethics among these cultures, a sample of workers in each country was invited to complete a questionnaire.

\section{Demographics}

The following statements briefly described the demographics of the respondents:

- Gender: The US and South Korean samples were about $1 / 2$ female, while the Omani and Bolivian samples were about $1 / 3$ female.

- Age: The Bolivian ( $\mathrm{B} \approx 30$ years), Omani $(\mathrm{B} \approx 32$ years), and South Korean ( $\mathrm{B} \approx 33$ years) samples were younger than the US sample ( $\mathrm{B} \approx 41$ years).

- Education: Most respondents in all samples were undergraduate degree holders.

- Position: The Bolivian sample had the most management-level respondents $(\sim 71 \%)$ followed by the South Korean and US samples ( 44\% and $\sim 41 \%$ ); the Omani sample contained the fewest management-level respondents $(\sim 20 \%)$.

\section{ANOVA Findings}

To explore the influence of cultural differences on the IS ethics of employees in Oman, South Korea, Bolivia and the western US, five null hypotheses were established for testing via ANOVA. Each is listed next with its accompanying dependent (DV) and independent (IV) variables:

Culture does not affect employee views on

1. Employee use of employer IS resources for personal entertainment.
$\mathrm{DV}=$ respondent's average response to all items in questionnaire section 1

IV = respondent's culture

2. Employee use of employer IS resources for gain (either their own or friends' or family's).

DV = respondent's average response to all items in questionnaire section 2

$\mathrm{IV}=$ respondent's culture

3. Employer monitoring of employee use of employer IS resources.

$\mathrm{DV}=$ respondent's average response to all items in questionnaire section 3

IV = respondent's culture

4. Use of IS resources in general (i.e., all of the issues combined).

DV = respondent's average response to all items in the questionnaire

IV = respondent's culture

5. Use of IS resources in specific circumstances

(i.e., each issue individually).

$\mathrm{DV}=$ respondent's response to each item in the questionnaire individually

IV = respondent's culture

The analysis results are presented next in a brief, non-tabular format:

Hypothesis 1: US and Omani respondents rated employee use of employer IS resources for personal entertainment as significantly more unethical than did Bolivian respondents, who in turn rated such activity as significantly more unethical than did South Korean respondents. All four cultures, however, yielded average responses on the unethical side of the rating scale midpoint.

Hypothesis 2: US respondents rated employee use of employer IS resources for personal, family, or friends' gain as significantly more unethical than did Omani, Bolivian, and South Korean respondents. All four cultures, however, yielded average responses on the unethical side of the rating scale midpoint.

Hypothesis 3: US respondents rated employer monitoring of employee use of employer IS resources as ethical. Omani and Bolivian respondents rated this activity as unethical, and South Korean respondents rated this activity as significantly more unethical still. This analysis was the only one of the first four to show an actual disagreement on the ethicality of an IS use, with Oman, Bolivia, and South Korea on the unethical side of the response scale midpoint and the USA on the ethical side.

Hypothesis 4: Culture yielded a weak but statistically significant result for the comparison of the overall survey mean across cultures. However, 
the effect was so weak that pairwise comparison of adjacent means yielded no significant differences. All four cultures yielded average responses on the same side of the rating scale midpoint.

Hypothesis 5: Culture yielded strong statistically significant results for 29 of the 30 scenarios on the survey. While space does not permit a full description of the analysis, we share the following observations:

- The one scenario that showed no significant difference (i.e., showed close agreement) among all four cultures was from section 2, relating to employee use of employer IS resources for gain. The scenario asked whether it is ethical for an employee to disclose sensitive customer information to an unauthorized third party without customer permission. The average response of each culture was that this is usually unethical.

- Only six scenarios yielded response averages on both sides of the response midpoint (i.e., yielded actual disagreement as to the ethicality of a scenario), and the South Korean sample generated five of them:

- Two scenarios were from Section 1, relating to employee use of employer IS resources for entertainment. The range of response averages for both scenarios was about 1 point or about $1 / 5$ of the response scale.

- South Koreans alone responded on average that it is usually ethical for employees to use employer computers to read online newspapers or magazines after work.

- South Koreans and Bolivians responded on average that it is usually ethical for employees to use employer computers to access an off-site personal email account after work.

- Four scenarios were from section 3, relating to employer monitoring of employee use of employer IS resources. The range of response averages for these scenarios was about $1 \frac{1 / 3}{3}$ points or $1 / 4$ of the response scale.

- South Koreans alone responded on average that it is usually unethical for employers to monitor employee e-mail after informing employees.

- South Koreans alone responded on average that it is usually unethical for employers to make surprise checks for personal documents on employer PCs after informing employees of the possibility.
- US respondents alone responded on average that it is usually ethical for employers to make surprise checks for non-employer software on employer PCs without informing employees of the possibility.

- South Koreans alone responded on average that it is usually unethical for employers to make surprise checks for non-employer software on employer PCs after informing employees of the possibility.

- The degree of agreement between culture pairs was measured by pairwise comparisons. These comparisons showed no significant difference (i.e., implied agreement) between culture pairs on 13 to 18 of the 30 scenarios:

○ Bolivia \& Oman agreed on 18.

- Bolivia \& South Korea agreed on 16.

- Oman \& the USA agreed on 14.

- Bolivia \& the USA agreed on 13.

- South Korea \& Oman agreed on 13.

- South Korea \& the USA agreed on 2.

Bolivia and Oman emerged as relatively centrist, while South Korea and the USA emerged as relatively extreme.

- Extreme response averages, i.e., the maximum or minimum average response for a scenario, were generated by

○ the USA on 24 scenarios,

- South Korea on 21 scenarios,

- Bolivia on 8 scenarios,

$\circ$ and Oman on 7 scenarios.

- Twenty-two of the thirty scenarios showed all cultures favoring employers over employees in the workplace. Of the remaining eight scenarios, five yielded employee favor by only one culture (South Korea in every case), one yielded employee favor by two cultures (Bolivia and South Korea), and one scenario yielded employee favor by three cultures (Bolivia, Oman, and South Korea); only one scenario, employers monitoring employee email without informing employees, yielded unanimous favor of employees.

- Oman emerged as the least cohesive sample, using standard deviation as a measure of withinsample agreement. The highest standard deviations were generated by

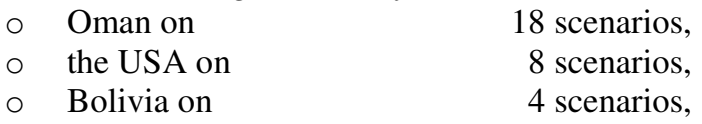


- and South Korea on

0 scenarios.

By the same token, South Korea yielded the most cohesive responses. The lowest standard deviations were generated by

\begin{tabular}{|c|c|c|}
\hline & South Korea on & 15 scenarios, \\
\hline & Bolivia on & 8 scenario \\
\hline & the USA on & 7 scenar \\
\hline & and Oman on & $\Omega_{\mathrm{c}}$ \\
\hline
\end{tabular}

ANOVA summary: Summarizing the results, we can say that the US sample yielded the most conservative responses, favoring employers' rights of ownership over employees' rights of possession. Regarding internal consistency, we observed that the Omani sample showed the least internal agreement, producing the highest standard deviations in more than half of the scenarios. The South Korean sample exhibited the lowest standard deviations overall. The South Korean respondents more often disagreed with the other samples on the ethicality of an item than did the Bolivian, Omani or US respondents. Most of the disagreement occurred over after-work activities and employer monitoring of employees. The differences of greatest magnitude occurred over employer monitoring of employees.

\section{Regression Findings}

Stepwise multiple regression analysis was used to estimate the strength of the effect of non-culture variables (sex, age, education level, and position) on responses. Since it was necessary to recode the culture variable, which contains nominal data, as a set of four dummy variables to conduct this analysis, the regression equation tested was

$$
\begin{aligned}
\mathrm{y}= & \beta_{1} \mathrm{x}_{1}+\beta_{2} \mathrm{x}_{2}+\beta_{3} \mathrm{x}_{3}+\beta_{4} \mathrm{x}_{4}+\beta_{5} \mathrm{x}_{5}+\beta_{6} \mathrm{x}_{6}+\beta_{7} \mathrm{x}_{7}+ \\
& \beta_{8} \mathrm{x}_{8}+e
\end{aligned}
$$

where y (the dependent variable) is the respondent rating of a scenario on the questionnaire, $e$ is the error term, and the independent variables are as follows:

$\mathrm{x}_{1}=$ Omani culture (yes/no)

$\mathrm{x}_{2}=$ South Korean culture (yes/no)

$\mathrm{x}_{3}=$ US culture (yes/no)

$\mathrm{x}_{4}=$ Bolivian culture (yes/no)

$\mathrm{x}_{5}=$ Age (in ordinal ranges)

$\mathrm{x}_{6}=$ Education level (in ordinal ranges)

$\mathrm{x}_{7}=$ Position (management/non-management)

$\mathrm{x}_{8}=\operatorname{Sex}($ male/female $)$

The independent variables were entered into the equation in every possible order and combination to see which accounted for the most variability in questionnaire responses. This was done four times: once aggregating each section of the questionnaire per respondent and once aggregating the questionnaire as a whole per respondent.

Stepwise multiple regression analysis of each section indicated that culture, age, and education level are the meaningful independent variables for section one, culture and age are the meaningful variables for section two, and culture is the meaningful variable for section three. Of the variables measured, culture had the largest effect. On the other hand, the percent of variation in responses explained by the optimal regression equation for each section was relatively low: $11 \%$ for section one, $10 \%$ for section two, and $22 \%$ for section three; this, of course, means that most of the variation in respondent scenario ratings was effected by a variable or variables not measured in this study.

\section{DISCUSSION AND CONCLUSIONS}

The results of this study indicate that, indeed, employees from the Republic of South Korea, the Sultanate of Oman, the Republic of Bolivia and the western USA do report statistically significant differences on most ethics issues in the questionnaire. Moreover, regression analysis shows that culture is the single greatest measured influence on responses. On the other hand, most of the statistically significant differences involved small magnitudes and did not cross the response midpoint. In other words, while the differences are not due to chance, neither do they represent actual disagreement about what is ethical and what is not. Rather, we see them as representing differing depths of commitment to the ethicality of a particular behavior.

We thus present as the major conclusion of this study that there is significant reason to assume strong agreement among the four cultures studied as to ethical uses of information systems resources in organizations. We see this agreement as a foundation from which disagreements can be successfully negotiated.

We noted that evidence suggests gender, age, education level, and employment position affect ethics attitudes: women and older people tend to favor employers over employees, as do people with more education and a higher employment position. We now note that this demographic profile fits somewhat the US sample and the Bolivian sample. The US sample was the most feminine and the oldest, and it most favored employers. The Bolivian sample was the most highly positioned in employment and 
had the highest education level within their respondents, and they also favored employers over employees in most scenarios. If US and Bolivian employees in general really possess these traits relative to Oman and South Korea, then all is well. However, if they do not, then the effect of the demographic variables is confounded with the effect of culture and we cannot say that our results are due to a culture effect.

Fortunately, the multiple regression analysis indicates that culture was the single most influential independent variable of those measured in the questionnaire, giving us empirical grounds for asserting a clear culture effect that, in total, outweighs the effect of any other variables measured.

Additionally, our study yielded some results that do not follow logically from simple demographics. The demographic profile of the Omani sample indicated that it should be the least conservative, but such was not the case. Generally South Korea was the least conservative. We see this as more evidence that, whatever confounding may have occurred; there is still a culture effect at work. Also the Bolivian sample should be the second most conservative, but it seems to be less conservative than the Omani sample but more conservative than the South Korean sample.

\section{REFERENCES}

1. Abeng T. (1997). Business ethics in Islamic context: Perspectives of a Muslim business leader. Business Ethics Quarterly, 7(3), 47-54.

2. Al-Lawatia, H. \& Hilton, T. S. E. (2002). Comparing IS ethics in the USA with IS ethics in the Arab world. In M. Khosrow-Pour (Ed.), Proceedings of the Annual Conference of the Information Resource Management Association International (IRMA International).

3. Arruda M. C. (Oct 1997). Business ethics in Latin America. Journal of Business Ethics. Dordrecht: 16(14), 1597-1604.

4. De Mente, B. (1988). Korean Etiquette and Ethics in Business, Lincolnwood, IL: NTC Business Books.

5. Kant, I., Hatfield, G. (Ed.), Ameriks, K. (Ed.), \& Clarke, D. M. (Ed.) (2004). Prolegomena to Any Future Metaphysics That Will Be Able to Come Forward as Science: With Selections from the
Critique of Pure Reason. Cambridge, England: Cambridge Texts in the History of Philosophy.

6. Kaplowitz, M.D., Hadlock, T.D., \& Levine, R. (2004). A Comparison of web and mail survey response rates. Public Opinion Quarterly, 68(1), 94-101.

7. Leonard, L.N.K., Cronan T.P. (2005). Attitude toward ethical behavior in computer use: A shifting model. Wembley, 105(9), 1150-1172.

8. Loch, K. D., Conger, S. \& Oz, E. (1998). Ownership, privacy and monitoring in the workplace: A debate on technology and ethics. Journal of Business Ethics, 17, 653-663.

9. Mill, J. S. \& Sher, G. (Ed.) (2002). Utilitarianism. Indianapolis, IN: Hackett Publishing Company.

10. Newton, L. H. \& Ford, M. M. (1994). Taking Sides: Clashing Views on Controversial Issues in Business Ethics and Society. Guilford, CT: The Dushkin Publishing Group, Inc.

11. Rawls, J. (1999). A Theory of Justice, Revised Edition. Cambridge, Massachusetts: Belknap Press.

12. Sharma, S. K. \& Gupta, J. M. D. Improving workers' productivity and reducing Internet abuse. The Journal of Computer Information Systems, 44(2), 74-79.

13. Thorne, L. \& Saunders, S. B. (2002). The sociocultural embeddedness of individuals' ethical reasoning in organizations (cross-cultural ethics). Journal of Business Ethics 35(1), 1-14.

14. Transparency International. (2006). How Do You Define Corruption? Retrieved May 28, 2006, from http://www.transparency.org/news _room/faq/corruption_faq\#faqcorr1.

15. Transparency International. (2006). Corruption Perceptions Index 2005. Retrieved May 28, 2006, from http://www.transparency.org/policy_ research/surveys_indices/cpi/2005.

16. Tsui, J. \& Windsor, C. (2001). Some crosscultural evidence on ethical reasoning. Journal of Business Ethics 31(2), 143-150.

17. Yum, J. O. (1987). Korean philosophy and communication. In D. L. Kincaid (Ed.), Communication Theory: Eastern and Western Perspectives. San Diego, CA: Academic Press, pp. 71-86. 